\title{
Association of performance in a stair-climbing test with complications and survival after lung cancer resection in the video-assisted thoracoscopic surgery era: population-based outcomes
}

\author{
Olli Helminen ${ }^{1,2}$, Johanna Valo $\mathbb{B}^{1,3}$, Heidi Andersen $\mathbb{B}^{4}$, Johan Söderström ${ }^{4}$ and Eero Sihvo ${ }^{1}$
}

${ }^{1}$ Dept of Surgery, Central Finland Central Hospital, Jyväskylä, Finland. ${ }^{2}$ Surgery Research Unit, Medical Research Center Oulu, Oulu University Hospital and University of Oulu, Oulu, Finland. ${ }^{3}$ Dept of General Thoracic and Esophageal Surgery, Heart and Lung Center, Helsinki University Hospital, Helsinki, Finland. ${ }^{4}$ Dept of Pulmonology, Vaasa Central Hospital, Vaasa, Finland.

Corresponding author: Eero Sihvo (eero.sihvo@ksshp.fi)

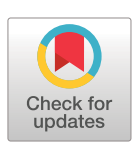

Copyright @The authors 2021

This version is distributed under the terms of the Creative Commons Attribution NonCommercial Licence 4.0. For commercial reproduction rights and permissions contact permissions@ersnet.org

This article has supplementary material available from https://openres.ersjournals.com

Received: 12 Feb 2021

Accepted: 23 April 2021

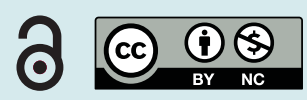

Shareable abstract (@ERSpublications)

According to stair-climbing-based testing, VATS surgery is safe, with similar major morbidity rates as in those with better exercise capacity. However, patients with poorer exercise capacity have significantly increased non-cancer-specific mortality. https://bit.ly/3aLB76w

Cite this article as: Helminen $\mathrm{O}$, Valo $\mathrm{J}$, Andersen $\mathrm{H}$, et al. Association of performance in a stairclimbing test with complications and survival after lung cancer resection in the video-assisted thoracoscopic surgery era: population-based outcomes. ERJ Open Res 2021; 7: 00110-2021 [DOI: 10.1183/23120541.00110-2021].

\section{Abstract}

Introduction With a population-based cohort in the video-assisted thoracoscopic surgery (VATS) era, we aimed to evaluate the value of the stair-climbing test (SCT) on short- and long-term outcomes of lung cancer surgery.

Methods All patients operated due to primary lung cancer in Central Finland and Ostrobothnia from 2013 to June 2020 were included. For the analysis, clinical variables including the outcome of SCT and causespecific mortality were available. Short- and long-term outcomes were compared between $<11 \mathrm{~m}(\mathrm{n}=66)$ and $>12$ m SCT ( $\mathrm{n}=217)$ groups.

Results Patients with poor performance $(<11 \mathrm{~m})$ had more comorbidities and worse lung function but did not differ in tumour stage or treatment. No differences between groups were observed in major morbidity rate $(10.6 \%$ versus $11.1 \%, \mathrm{p}=0.918$ ) or median hospital stay (5 (IQR 4-7) versus 4 (IQR 3-7), $\mathrm{p}=0.179$ ). At 1-year, fewer patients were alive and living at home in the climbing $<11 \mathrm{~m}$ group $(81.3 \%)$ compared to the $>12$ m group (94.2\%), $\mathrm{p}=0.002$. No difference was observed in cancer-specific 5-year survival. Noncancer-specific survival (62.9\% versus $83.1 \%, \mathrm{p}<0.001)$ and overall survival $(49.9 \%$ versus $70.0 \%$, $\mathrm{p}<0.001$ ) were worse in the $<11 \mathrm{~m}$ group. After adjustment for confounding factors, SCT remained as a significant predictor for non-cancer-specific (HR 4.28; 95\% CI 2.10-8.73) and overall mortality (HR 2.38; 95\% CI 1.43-3.98).

Conclusions With SCT-based exercise testing, VATS can be performed safely, with a similar major morbidity rate in the poor performance group $(<11 \mathrm{~m})$ compared to $>12 \mathrm{~m}$ group. Poor exercise performance increases non-cancer-specific mortality. Being a major predictor of survival, exercise capacity should be included in prognostic models.

\section{Introduction}

The guideline-based recommendation for treatment of early-stage lung cancer is surgery. However, surgery is associated with significant morbidity and mortality. The 30-day mortality reported recently by the European Society of Thoracic Surgeons Database was 2.6\% [1]. At 90 days, the 30-day mortality rate of $2.3 \%$ in the Finnish population-based series almost doubled to $4.3 \%$ [2]. The risk of perioperative mortality and morbidity must therefore be weighed against the long-term benefits of surgery. 
In both European Respiratory Society (ERS)/European Society of Thoracic Surgeons (ESTS) and American College of Chest Physicians (ACCP) guidelines, the preoperative physiological assessment is recommended to include the evaluation of cardiovascular risk and lung functions [3, 4]. With either forced expiratory volume in $1 \mathrm{~s}\left(\mathrm{FEV}_{1}\right)$ or diffusing capacity of the lung for carbon monoxide $\left(D_{\mathrm{LCO}}\right)$ below $80 \%$, ERS/ESTS guidelines recommend formal cardiopulmonary exercise testing (CPET) with measurement of maximal oxygen uptake ( $\left.V_{\mathrm{O}_{2}}^{\prime} \max \right)$. For this formal CPET, in both ACCP and ERS/ESTS guidelines, a stair-climbing test (SCT) can be used as a screening test. In both guidelines, the threshold for suboptimal performance was set at $22 \mathrm{~m}$ [4].

In the era of open lung cancer surgery, several studies have evaluated the role of SCT in the assessment of preoperative exercise capacity and complication risk. According to a recent review, SCT is able to predict complication [5]. In this review, the threshold for a poor result and referral to formal cardiopulmonary exercise testing was set at $10 \mathrm{~m}$ [5]. The role of SCT in the preoperative physiological assessment has, however, never been evaluated in the era of minimally invasive lung cancer surgery.

We have shown, at the population level, the benefits of a modern guideline-based approach in the preoperative evaluation and treatment of lung cancer patients for the short- and long-term outcomes [6]. The preoperative physiological assessment included symptom-limited SCT and selective referral to formal cardiopulmonary exercise testing with a result of $<9 \mathrm{~m}$. Our aim was, in the era of video-assisted thoracoscopic surgery (VATS), to evaluate the predictive value of this stair-climbing-based testing of exercise capacity on the short- and long-term outcomes of population-based lung cancer surgery. The primary outcome was major complications. Secondary outcomes were alive and able to live at home at 1 year after surgery, and 5-year estimated overall and disease-specific survival. We hypothesised that SCT could predict these outcomes.

\section{Materials and methods}

\section{Design}

Since September 2012, a modern guideline-based treatment of lung cancer has been implemented in Central Finland Central Hospital [6]. From Ostrobothnia, lung cancer surgery was centralised to Central Finland Central Hospital in October 2014. Between January 1, 2013 and June 30, 2020, all patients diagnosed and resected with a primary lung cancer in Central Finland and Ostrobothnia were included in this population-based cohort study. Patients who underwent surgical resection were identified from hospital records and the prospective surgical database and confirmed by data from the Finnish Cancer Registry. The follow-up ended on August 10, 2020. The acquisition of individual patient data from hospital records was approved by the local hospital districts. The National Institute for Health and Welfare of Finland (permissions no: THL/143/5.05.00/2015 and THL/1349/5.05.00/2015) and Statistics Finland (TK53-1410-15) approved the study.

\section{Data collection}

All Finnish residents are listed by their individually unique and immutable 10-digit national registration numbers in the hospital databases and several national databases. This allows reliable identification of patients from hospital records and the Finnish Cancer Registry, as well as linkage of data. The Finnish Cancer Registry is population-based and covers all parts of Finland. Registration includes the municipality and, therefore, the hospital district where the patient lives. According to Finnish healthcare policy, all hospital districts are responsible for arranging specialised care for residents in their area. In Central Finland and Ostrobothnia, which had a total population of 456976 as of December 31, 2017 (8.3\% of the Finnish population), the treatment of lung cancer is organised by Central Finland Central Hospital and Vaasa Central Hospital, respectively. Using the histopathological, clinical follow-up, and discharge registries of the two hospitals, all patients diagnosed with primary lung cancer who underwent lung resection with curative intent between January 1, 2013 and June 30, 2020 were identified. Cross-linking of Finnish Cancer Registry data and hospital databases confirmed identification of all surgical cases. From 2015, a prospective surgical database established in Central Finland Central Hospital in 2012 provided the surgical cases. Variables in this database were not designed for this study and the data for all study patients were therefore re-reviewed from hospital records.

\section{Evaluation of physical performance}

The protocol of preoperative evaluation in the clinical practice and the formation of study groups is presented in figure 1. All surgical candidates were sent a preoperative questionnaire including two questions on physical performance: the ability to climb stairs and walking speed. A reported good physical performance included the ability to climb three or more flights of stairs and walk at least at a speed of $5 \mathrm{~km} \cdot \mathrm{h}^{-1}$. The physical performance was further confirmed by the operating surgeon at the preoperative clinic. 
287 resected patients

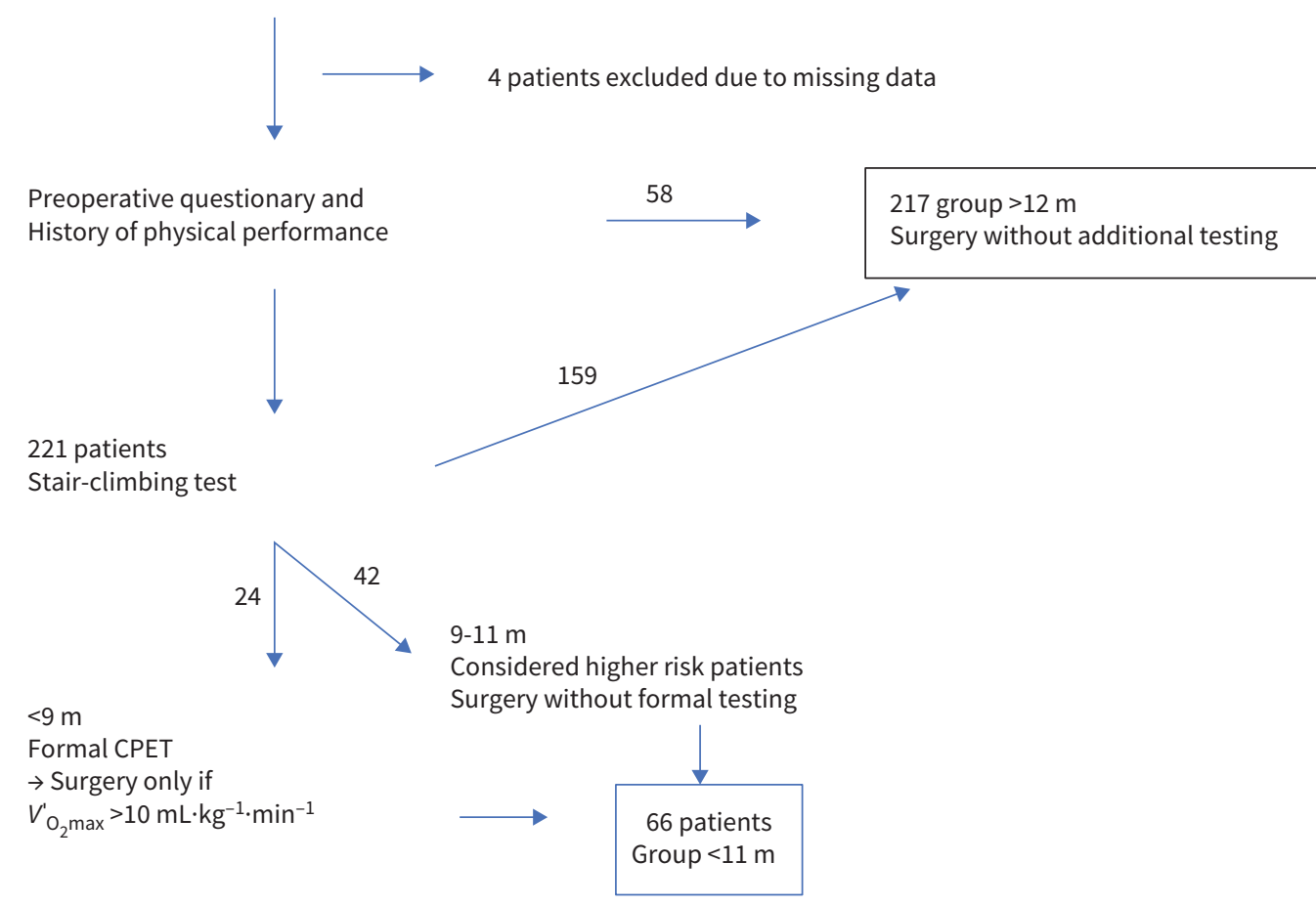

FIGURE 1 Flowchart showing preoperative determination of physical performance and formation of study groups. $V^{\prime}{ }_{2}$ max: maximal oxygen uptake.

Only those patients $(n=58)$ able to do heavy work, to climb more than four floors routinely or participate in strenuous sports such as cross-country skiing were not tested further before surgery. These patients were placed in the study group $>12 \mathrm{~m}$. Four patients were excluded from the analysis due to lack of any reported data of physical performance. Of 287 operated patients, 221 underwent a symptom-limited SCT up to a maximum of four flights $(14.1 \mathrm{~m})$. Only two candidates for a pneumonectomy were tested up to five flights $(17.6 \mathrm{~m})$. Of these 221 patients, 159 climbed $>12 \mathrm{~m}$. In this group, nine patients (5.7\%), mostly early referrals from Ostrobothnia, underwent a formal CPET with a mean $V_{\mathrm{O}_{2}}^{\prime}$ max of $18.1 \mathrm{~mL} \cdot \mathrm{kg}^{-1} \cdot \mathrm{min}^{-1}$. These 159 patients together with the previously mentioned 58 patients formed the study group including 217 patients able to climb $>12 \mathrm{~m}$ (3.5 flights, i.e. $12.3 \mathrm{~m}$ ). Since during the test patients finished their climb after a full or half flight, there were no results for between 3 and 3.5 flights (or $10.6 \mathrm{~m}$ to 12.3). In this study, we used three flights of $10.6 \mathrm{~m}$ as a threshold for poor exercise capacity, being very close to a previously recommended level of $10 \mathrm{~m}$ [5]. Of 221 patients tested, 66 climbed this $10.6 \mathrm{~m}$ or less and formed the $<11 \mathrm{~m}$ study group. Of these 66,42 climbed three flights equal to $10.6 \mathrm{~m}$. Although in our practice these patients are considered to be at increased surgical risk, they undergo a formal CPET only very selectively. In this group, the rate was $11.9 \%(\mathrm{n}=5)$ with a mean $V_{\mathrm{O}_{2}}$ max of $14.2 \mathrm{~mL} \cdot \mathrm{kg}^{-1} \cdot \mathrm{min}^{-1}$. Those patients unable to climb $>2.5$ flights $(8.8 \mathrm{~m})$ are recommended to undergo a formal CPET and were considered unsuitable for surgery with $V_{\mathrm{O}_{2}}^{\prime}$ max under $10 \mathrm{~mL} \cdot \mathrm{kg}^{-1} \cdot \mathrm{min}^{-1}$. The rate of formal CPET in this group of patients $(\mathrm{n}=22)$ was $66.7 \%$ with a mean $V_{\mathrm{O}_{2}}^{\prime} \max$ of $12.3 \mathrm{~mL} \cdot \mathrm{kg}^{-1} \cdot \mathrm{min}^{-1}$.

\section{Outcomes and definitions}

The 8th edition of the TNM (tumour, node, metastasis) classification was used for staging. This required recoding all necessary surgical patients accordingly. Primary outcomes were major complications. Secondary outcomes were alive and able to live at home at 1 year after surgery, and 5-year estimated overall and disease-specific survival. Complications were graded according to the Clavien-Dindo classification [7]. Major complication was defined as higher than class II. Secondary outcomes were hospital stay, intensive care unit stay and home discharge rate. The ability to live at home was defined as the proportion of patients, out of all operated patients, who, 1 year after surgery, were living at home instead of a nursing facility, hospital or terminal care unit, or death. 


\section{Statistical analysis}

We constructed Kaplan-Meier survival curves according to the life table method to visualise the crude all-cause and recurrence-free survival up to 5 years after surgery. Proportions, means and median values of other measured variables were compared using the chi-squared test, Mann-Whitney U-test and t-test as appropriate. The regression models were adjusted for potential confounding factors: age $\geqslant 80$ years, sex (male, female), Charlson comorbidity index (CCI) $\geqslant 5$, predicted post-operative (ppo) $\mathrm{FEV}_{1} \leqslant 50 \%$, $\mathrm{ppo} D_{\mathrm{LCO}} \leqslant 50 \%$, tumour histology, tumour stage (I, II, III-IV) and neo- or adjuvant treatment (yes/no). For regression analysis, multiple imputation was performed to cover missing values. The following proportions of variables were imputed: smoking in $2.4 \%$, ppoFEV in $1.4 \%$ and ppo $D_{\text {LCO }}$ in $7.7 \%$ For patients who received neoadjuvant treatment, clinical stage was used instead of pathological stage. All statistical analyses were performed using IBM SPSS 26.0 (IBM Corp., Armonk, NY, USA).

Results

Preoperative patient evaluation

Overall population-based outcomes in 287 operated patients had a major morbidity rate of 10.8\%, 30-day mortality rate of $0.3 \%$ and 90 -day mortality rate of $1.4 \%$. One-year and 5-year overall survival rates were $94.0 \%$ and $64.2 \%$, respectively. Four patients were excluded due to missing reported data of physical performance. The median age of the 283 included patients was 71 . The majority were male (63.6\%), had a CCI equal to or more than 1 (73.9\%), and were diagnosed with adenocarcinoma (59.4\%) and pathological stage IA disease (50.2\%). Overall, $66.7 \%$ of all operated patients had either $\mathrm{FEV}_{1} \%$ or $D_{\mathrm{LCO}}<80 \%$. Patient baseline characteristics stratified by the result of SCT are presented in table 1.

\section{Comparison by physical performance and treatment}

Surgical procedures and related oncological therapies are summarised in table 2. Overall VATS rate and the rate during the last 5 years was $78.7 \%$ and $88.2 \%$, respectively. This rate or the type of lung resection did not differ between the groups. A trend $(\mathrm{p}=0.088)$ in the rate of mediastinal lymphadenectomy was detected between $<11 \mathrm{~m}$ and $>12 \mathrm{~m}$ groups (78.8\% versus $85.7 \%)$. A similar trend $(\mathrm{p}=0.088)$ in lymph node yield was observed with medians of 10 and 12, respectively (table 2).

\section{Short-term outcomes}

Of 283 included patients, rates of major morbidity were $10.8 \%$, 30-day mortality $0.4 \%$ and 90-day mortality $1.4 \%$. The specific cause of death at 90 days was cardiovascular or respiratory in all cases (table 3). Of these four deaths, two occurred at home, both in the $<11 \mathrm{~m}$ group after normal discharge. Physical performance had no effect on short-term complications (table 2). The major complication and 90-day mortality rates in the $<11 \mathrm{~m}$ and $>12 \mathrm{~m}$ groups were $10.6 \%$ and $11.1 \%(\mathrm{p}=0.918)$ and $3 \%$ and $0.9 \%(p=0.204)$, respectively. Median hospital stay was 5 (IQR 4-7) and 4 (3-7) days ( $p=0.179)$. With a cut-off of $9 \mathrm{~m}$ in physical performance between groups, major morbidity rates are $20.8 \%$ (5 out of 24) in the poor performance group and $10.0 \%$ (26 out of 259$)$ in the better performance group $(p=0.105)$.

\section{One-year outcome}

At 1 year, a major difference between the $<11 \mathrm{~m}$ and $>12 \mathrm{~m}$ group was observed in the number of patients living at home $(81.3 \%$ versus $94.2 \%, \mathrm{p}=0.002)$ (table 2$)$. The leading cause in the $<11 \mathrm{~m}$ group was other than lung cancer specific in $14.1 \%$, compared to $3.2 \%$ in the $>12 \mathrm{~m}$ group ( $\mathrm{p}=0.001$ ). Lung-cancer-specific death or disease recurrence was the reason for not living at home in $4.7 \%$ and $2.6 \%$, respectively. In adjusted analysis, the risk of inability to live at home 1 year after surgery was associated with the result of SCT, age at surgery, comorbidity burden, $\mathrm{ppo} D_{\mathrm{LCO}} \%$ and stage (table 4 ).

\section{Long-term outcome}

Overall survival was worse in the $<11 \mathrm{~m}$ group (49.9\% versus $70.0 \%, \mathrm{p}<0.001$, figure $2 \mathrm{a}$ ). No difference existed between study groups in lung-cancer-specific 5-year survival (figure 2b), but a major difference was seen in non-cancer-specific survival (figure 2c, table 2). Of the 31 deaths in the $<11 \mathrm{~m}$ group, the cause of death was lung cancer in 9 (29.0\%) patients, and of the 42 deaths in the $>12 \mathrm{~m}$ group, the cause of death was lung cancer in $23(54.8 \%)$ patients $(\mathrm{p}=0.029)$. Causes of death in the study groups are listed in table 3 .

Age $\geqslant 80$ years (figure $3 \mathrm{a}, \mathrm{p}=0.201$ ), $\mathrm{ppoFEV}_{1} \% \leqslant 50 \%$ (figure $3 \mathrm{~b}, \mathrm{p}=0.294$ ) and $\mathrm{ppo} D_{\mathrm{LCO}} \% \leqslant 50 \%$ (figure 3c, $\mathrm{p}=0.085$ ) had no significant impact on non-cancer-specific survival. Decreased non-cancer-specific survival was detected in patients with increased comorbidity burden (CCI $\geqslant 5$ ) (figure $3 d, p=0.018$ ). None of these variables had a significant effect on cancer-specific survival (data not shown). 
TABLE 1 Baseline and tumour characteristics in stair-climbing test groups

\begin{tabular}{|c|c|c|c|c|}
\hline & All patients & $<11 \mathrm{~m}$ stairs & $>12$ m stairs & p-value \\
\hline Subjects $\mathrm{n}$ & 283 & 66 & 217 & \\
\hline Age years & $71(64-76)$ & $71(66-76)$ & $71(64-76)$ & 0.404 \\
\hline $\mathrm{BMI} \mathrm{kg} \cdot \mathrm{m}^{-2}$ & $26.1 \pm 4.4$ & $27.4 \pm 6.1$ & $25.7 \pm 3.7$ & 0.033 \\
\hline Male & $180(63.6)$ & $39(59.1)$ & $141(65)$ & 0.384 \\
\hline Charlson comorbidity index & & & & 0.012 \\
\hline 0 & 74 (26.1) & $6(9.1)$ & 68 (31.3) & \\
\hline 1 & $79(27.9)$ & $22(33.3)$ & $57(26.3)$ & \\
\hline 2 & $59(20.8)$ & $16(24.2)$ & $43(19.8)$ & \\
\hline $3-4$ & $51(18.0)$ & $13(19.7)$ & $38(17.5)$ & \\
\hline 5 or higher & $20(7.1)$ & $9(13.6)$ & $11(5.1)$ & \\
\hline Smoking history & & & & 0.017 \\
\hline Never & $54(19.1)$ & $10(15.2)$ & $44(20.3)$ & \\
\hline Former & $117(41.3)$ & $20(30.3)$ & $92(42.4)$ & \\
\hline Current & $112(39.6)$ & $36(54.5)$ & $74(34.1)$ & \\
\hline Stair-climbing height m & $12.9 \pm 2.7$ & $8.8 \pm 3.0$ & $14.1 \pm 0.4$ & $<0.001$ \\
\hline$V_{\mathrm{O}_{2}}^{\prime} \operatorname{max~} \mathrm{mL} \cdot \mathrm{kg}^{-1} \cdot \min ^{-1}(\mathrm{n}=36)$ & $15.2 \pm 19.4$ & $12.8 \pm 1.6$ & $19.1 \pm 3.7$ & $<0.001$ \\
\hline FEV $_{1} \%$ pred & $80.8 \pm 19.4$ & $71.6 \pm 17.7$ & $81.9 \pm 18.7$ & $<0.001$ \\
\hline ppoFEV $_{1} \%$ & $67.7 \pm 17.3$ & $60.6 \pm 14.7$ & $69.7 \pm 17.6$ & $<0.001$ \\
\hline$D_{\text {Lco }} \%$ & $79.7 \pm 19.3$ & $72.7 \pm 19.7$ & $81.9 \pm 18.7$ & 0.001 \\
\hline $\mathrm{ppo} D_{\mathrm{Lco}} \%$ & $67.3 \pm 17.1$ & $62.3 \pm 16.2$ & $67.6 \pm 17.4$ & 0.006 \\
\hline Histology & & & & 0.001 \\
\hline Adenocarcinoma & $168(59.4)$ & $27(40.9)$ & $141(65)$ & \\
\hline Squamous cell cancer & $81(28.6)$ & $30(45.5)$ & $51(23.5)$ & \\
\hline Other & $33(11.7)$ & $9(13.6)$ & $25(11.5)$ & \\
\hline Tumour size $\mathrm{cm}$ & $2.3(1.5-4.0)$ & $2.6(1.8-4.1)$ & $2.2(1.5-4.0)$ & 0.135 \\
\hline PET-CT & $218(77.0)$ & $53(80.3)$ & $165(76)$ & 0.471 \\
\hline Invasive staging & $67(23.7)$ & $17(25.8)$ & $50(23)$ & 0.649 \\
\hline Pathological UICC stage ${ }^{\#}$ & & & & 0.865 \\
\hline I & $174(61.5)$ & $42(63.6)$ & $132(60.8)$ & \\
\hline II & $67(23.7)$ & $14(21.2)$ & $53(24.4)$ & \\
\hline III-IV & $42(14.8)$ & $10(15.2)$ & 32 (14.7) & \\
\hline
\end{tabular}

Data are presented as median (interquartile range), mean \pm SD or $n(\%)$, unless otherwise stated. BMI: body mass index; $V_{\mathrm{O}_{2}}^{\prime}$ max: maximal oxygen uptake; $\mathrm{FEV}_{1}$ : forced expiratory volume in $1 \mathrm{~s}$; ppo: predicted post-operative; $D_{\text {Lco }}$ : diffusing capacity of the lung for carbon monoxide; PET-CT: positron emission tomography-computed tomography; UICC: Union for International Cancer Control. " : patients who received neoadjuvant treatment were classified according to clinical stage.

In the multivariable analyses of 5-year outcomes, the result of SCT was an important risk factor for both overall (HR 2.38, 95\% CI 1.43-3.98) and non-cancer-specific (HR 4.28, 95\% CI 2.10-8.73) mortality (table 4). The only other similarly important predictor was CCI $\geqslant 5$ (table 4).

\section{Discussion}

This study differentiates at the population-level the influence of exercise capacity measured by SCT on outcomes of lung cancer surgery in the VATS era. VATS can be performed safely, with a similar major morbidity rate in the poor performance group $(<11 \mathrm{~m})$ compared to the $>12 \mathrm{~m}$ exercise capacity group. A poor performance in SCT had a major impact on the ability to live at home 1 year after surgery and on long-term non-cancer-specific and overall survival. Being a powerful predictor of survival, exercise capacity should be included in routine prognostic models.

In ERS/ESTS and ACCP guidelines, based on the data from open surgery era, the SCT threshold for safe lung cancer surgery was set at $22 \mathrm{~m}[3,4]$. Contrary to these recommendations, in our practice in the VATS era we set the threshold in SCT for increased risk at $11 \mathrm{~m}$ and the threshold for formal exercise testing at $9 \mathrm{~m}$. In our highly selective formal testing policy, a contraindication for any lung cancer surgery, as in both ERS/ESTS and ACCP guidelines, was a peak oxygen consumption of $<10 \mathrm{~mL} \cdot \mathrm{kg}^{-1} \cdot \mathrm{min}^{-1}[3,4]$. By following these modified guideline-based recommendations in exercise testing in this population-based series, a low $0.3 \%$ 30-day and 1.4\% 90-day overall mortality was reached. No difference was detected between the SCT groups in the rate of any complications, major morbidity, mortality or hospital stay. 


\begin{tabular}{|c|c|c|c|c|}
\hline & All patients & $<11 \mathrm{~m}$ stairs & $>12 \mathrm{~m}$ stairs & p-value \\
\hline Subjects $\mathrm{n}$ & 283 & 66 & 217 & \\
\hline \multicolumn{5}{|l|}{ Operative approach } \\
\hline VATS & $226(79.9)$ & $56(84.8)$ & $170(78.3)$ & 0.248 \\
\hline Type of surgery & & & & 0.394 \\
\hline Pneumonectomy & $3(1.1)$ & & $3(1.4)$ & \\
\hline Bilobectomy & $4(1.4)$ & & $4(1.8)$ & \\
\hline Lobectomy & $165(58.3)$ & $35(53.0)$ & $130(59.9)$ & \\
\hline Segmentectomy & $96(33.9)$ & $25(37.9)$ & $71(32.7)$ & \\
\hline Wedge & $9(3.2)$ & $4(6.1)$ & $5(2.3)$ & \\
\hline Combination & $5(1.8)$ & $2(3.0)$ & $3(1.4)$ & \\
\hline Bronchus & $1(0.4)$ & & $1(0.5)$ & \\
\hline Lymph node dissection & & & & 0.088 \\
\hline $\mathrm{NoN} \mathrm{N}_{2}$ & $24(8.5)$ & $5(7.6)$ & $19(8.8)$ & \\
\hline $\mathrm{N}_{2}$ sampling $^{\#}$ & $21(7.4)$ & $9(13.6)$ & $12(5.5)$ & \\
\hline Systematic $\mathrm{N}_{2}$ dissection & $238(84.1)$ & $52(78.8)$ & $186(85.7)$ & \\
\hline Lymph nodes examined & $12(7-16)$ & $10(5-15)$ & $12(8-16)$ & 0.114 \\
\hline \multicolumn{5}{|l|}{ Oncological therapy } \\
\hline Neoadjuvant & $33(11.7)$ & $5(7.6)$ & $28(12.9)$ & 0.238 \\
\hline Adjuvant & $61(21.6)$ & $12(18.2)$ & $49(22.6)$ & 0.447 \\
\hline \multicolumn{5}{|l|}{ Complications } \\
\hline Any type & $94(33.2)$ & $23(34.8)$ & $71(32.7)$ & 0.748 \\
\hline Minor, CDC grade I-II & $63(22.3)$ & $16(24.2)$ & $47(21.7)$ & 0.659 \\
\hline Major, CDC grade IIla-V & $31(11.0)$ & $7(10.6)$ & $24(11.1)$ & 0.918 \\
\hline \multicolumn{5}{|l|}{ Mortality } \\
\hline 30-day & $1(0.4)$ & 0 & $1(0.5)$ & 0.581 \\
\hline 90-day & $4(1.4)$ & $2(3.0)$ & $2(0.9)$ & 0.204 \\
\hline Hospital stay days & $5(3-7)$ & $5(4-7)$ & $4(3-7)$ & 0.179 \\
\hline Discharged to home & $233(82.3)$ & $50(75.8)$ & $183(84.3)$ & 0.110 \\
\hline 1-year alive and at home & $230(90.9)$ & $52(81.3)$ & $178(94.2)$ & 0.002 \\
\hline \multicolumn{5}{|l|}{ Survival \% } \\
\hline 5-year overall & 64.7 & 49.9 & 70.0 & $<0.001$ \\
\hline 5-year cancer-specific & 83.0 & 79.3 & 84.3 & 0.458 \\
\hline 5-year non-cancer-specific & 77.9 & 62.9 & 83.1 & $<0.001$ \\
\hline
\end{tabular}

With a high VATS rate of $88.2 \%$ during the last 5 years together with a segmentectomy rate of $33.9 \%$ in our population-based series, SCT can be used as a safe screening tool for a highly selective formal CPET. Therefore, in the VATS era, SCT can be relied on more widely in exercise testing, and the threshold for a poor test result and need for formal exercise testing could be set even below the recently recommended threshold of $10 \mathrm{~m}$ [5]. With a $9 \mathrm{~m}$ cut-off in this study, a trend of increased major morbidity rate in the poorer performance group (20.8\% versus $10.0 \%$ ) is evident. With current ERS/ESTS recommendations, the need for formal CPET in this series would have been $66.7 \%$. With our SCT screening and highly selective formal testing, the need for CPET is around $10 \%$ at the population-level. This limits the costs of preoperative formal stress testing without compromising the outcome of lung cancer surgery.

In addition to preventing unnecessary morbidity and mortality, the aim of the preoperative physiological evaluation is to prevent chronic disability [4, 8]. Survival and the ability to live at home at 1 year post-operatively was significantly reduced in the $<11 \mathrm{~m}$ group, with a rate of $78.8 \%$ compared to $94.2 \%$ in the $>12 \mathrm{~m}$ group. Multivariable analysis revealed the following independent predictors for this outcome: performance in SCT, age, CCI, ppo $D_{\mathrm{LCO}}$ and stage III disease. The cause of death was rarely cancer-related. Therefore, poor performance in SCT is associated with early death related to other causes and chronic disability after surgery. Overall, exercise capacity is a better predictor of survival than cardiovascular risk factors [9]. Of previous predictors of 1-year outcome, only performance in SCT and CCI were predictors of overall long-term mortality in the multivariable analysis. Contrary to a previous suggestion, worse survival associated with impaired physical performance was solely explained by the increase in death from 


\begin{tabular}{|lcc|}
\hline TABLE 3 Cause of death by group & & $>12 \mathrm{~m}$ \\
\hline Group & $<11 \mathrm{~m}$ & 217 \\
\hline Subjects $\mathrm{n}$ & 66 & $42(19.4)$ \\
\hline Any cause & $31(46.9)$ & $23(10.6)$ \\
\hline Lung cancer & $9(13.6)$ & $19(8.8)$ \\
\hline Other & $22(33.3)$ & $4(1.8)$ \\
\hline Respiratory & $8(12.1)$ & $4(1.8)$ \\
\hline Cardiac & $3(4.5)$ & $3(1.4)$ \\
\hline Nervous system & $2(3.0)$ & $1(0.4)$ \\
\hline Gastrointestinal & $3(4.5)$ & $3(1.4)$ \\
\hline Another cancer & $3(4.5)$ & $0(0.0)$ \\
\hline Septicaemia & $1(1.5)$ & $1(0.5)$ \\
\hline Pelvic fracture & $0(0.0)$ & $2(0.9)$ \\
\hline Alcoholism & $0(0.0)$ & $1(0.5)$ \\
\hline Suicide & $0(0.0)$ & $0(0.0)$ \\
\hline Sudden death without disease recurrence & $2(3.0)$ & \\
\hline Data are presented as $\mathrm{n}(\%)$. & & \\
\hline
\end{tabular}

non-cancer causes [10]. An increased risk of death due to lung cancer has previously been associated with a lower $V_{\mathrm{O}_{2}}^{\prime} \max$, a shorter shuttle walk distance, poorer exercise tolerance in SCT or even poorer self-rated physical fitness [10-12]. This prognostic role has several potential consequences. First, any risk models for long-term survival such as the STS-GTSD-Medicare long-term risk model or Eurolung2 should include some form of exercise testing [13, 14]. Second, besides stage, any comparisons of outcomes between treatment modalities such as stereotactic body radiation therapy (SBRT) and surgery should include exercise capacity, in addition to comorbidity burden and lung functions. Third, physical fitness is a modifiable prognostic factor and could therefore be improved by rehabilitation programmes [15]. Last, exercise tolerance could potentially be incorporated in future multifactorial mixed prognostic models to improve the selection of the most appropriate treatment modality for high-risk patients.

TABLE 4 Odds ratios with 95\% confidence intervals of alive or at home 1-year after surgery, and hazard ratios (HRs) with $95 \%$ confidence intervals of recurrence risk and mortality of common risk factors and stair-climbing test for lung cancer adjusted for confounding factors

\begin{tabular}{|c|c|c|c|c|}
\hline Variable & $\begin{array}{l}\text { Not alive or not at home } \\
1 \text { year after surgery OR } \\
\qquad(95 \% \mathrm{Cl})\end{array}$ & $\begin{array}{c}\text { Lung-cancer-specific } \\
\text { mortality HR } \\
(95 \% \mathrm{Cl})\end{array}$ & $\begin{array}{c}\text { Non-cancer-specific } \\
\text { mortality HR } \\
(95 \% \mathrm{Cl})\end{array}$ & $\begin{array}{c}\text { Overall mortality } \\
\text { HR } \\
(95 \% \mathrm{Cl})\end{array}$ \\
\hline $\begin{array}{l}\text { Stair climbing }<11 \mathrm{~m} \text { versus } \\
>12 \mathrm{~m} \text {, adjusted }\end{array}$ & $3.82(1.28-11.4)$ & $1.25(0.55-2.85)$ & $4.28(2.10-8.73)$ & $2.38(1.43-3.98)$ \\
\hline $\begin{array}{l}\text { Age at surgery }>80 \text { years versus } \\
<80 \text { years, adjusted }\end{array}$ & $9.82(2.31-41.8)$ & $1.08(0.28-4.11)$ & $3.38(1.20-9.48)$ & $1.97(0.89-4.35)$ \\
\hline Male sex versus female, adjusted & $0.54(0.18-1.66)$ & $1.11(0.51-2.43)$ & $2.86(1.27-6.45)$ & $1.76(1.01-3.07)$ \\
\hline $\begin{array}{l}\text { Former smoker versus never, } \\
\text { adjusted }^{\#}\end{array}$ & NA & $1.99(0.53-7.50)$ & $1.73(0.61-4.87)$ & $1.82(0.82-4.06)$ \\
\hline $\begin{array}{l}\text { Current smoker versus never, } \\
\text { adjusted }^{\#}\end{array}$ & NA & $2.21(0.56-8.78)$ & $1.43(0.50-4.12)$ & $1.65(0.72-3.81)$ \\
\hline $\begin{array}{l}\text { Charlson comorbidity index } \geqslant 5 \\
\text { versus }<5 \text { points, adjusted }{ }^{\#}\end{array}$ & $5.57(1.38-22.6)$ & $2.90(0.90-9.35)$ & $3.40(1.21-9.54)$ & $2.79(1.32-5.90)$ \\
\hline $\begin{array}{l}\text { ppoFEV }_{1} \leqslant 50 \% \text { versus }>50 \% \text {, } \\
\text { adjusted }^{\#}\end{array}$ & $1.81(0.55-5.98)$ & $0.86(0.34-2.16)$ & $1.65(0.70-3.87)$ & $1.14(0.62-2.10)$ \\
\hline $\begin{array}{l}\text { ppo } D_{\text {Lco }} \leqslant 50 \% \text { versus }>50 \%, \\
\text { adjusted }^{\#}\end{array}$ & $4.33(1.27-14.8)$ & $0.96(0.37-2.48)$ & $1.81(0.79-4.14)$ & $1.43(0.78-2.63)$ \\
\hline $\begin{array}{l}\text { Adenocarcinoma versus squamous } \\
\text { cell cancer, adjusted }{ }^{\#}\end{array}$ & $1.35(0.41-4.47)$ & $1.54(0.63-3.74)$ & $1.69(0.78-3.67)$ & $1.50(0.85-2.63)$ \\
\hline Stage II versus stage I, adjusted ${ }^{\#}$ & $2.50(0.62-9.98)$ & $3.27(1.23-8.68)$ & $1.27(0.57-2.81)$ & $1.66(0.92-3.02)$ \\
\hline Stage III versus stage I, adjusted & $8.18(1.53-43.7)$ & $5.75(1.75-18.9)$ & $0.44(0.08-2.31)$ & $2.04(0.89-4.70)$ \\
\hline
\end{tabular}


a)

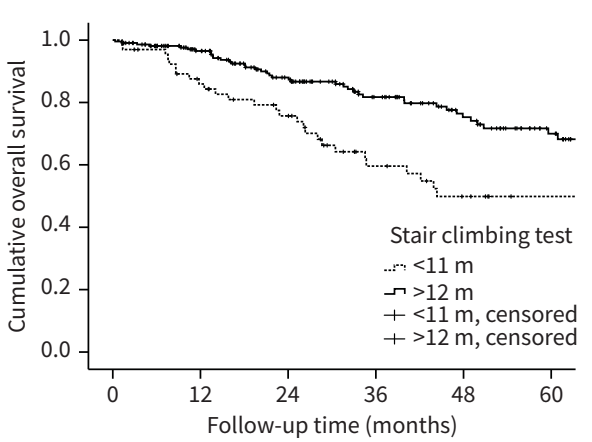

b)

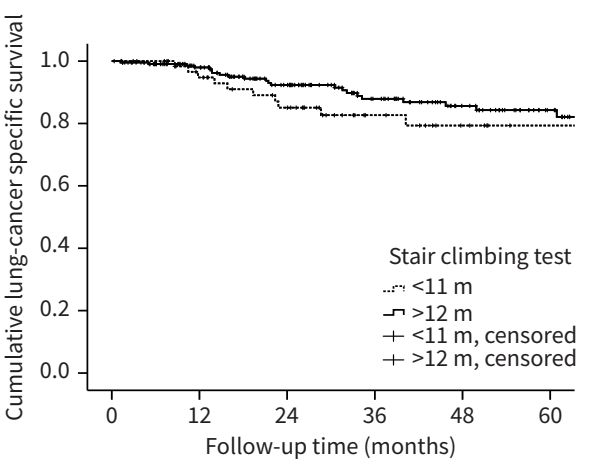

c)

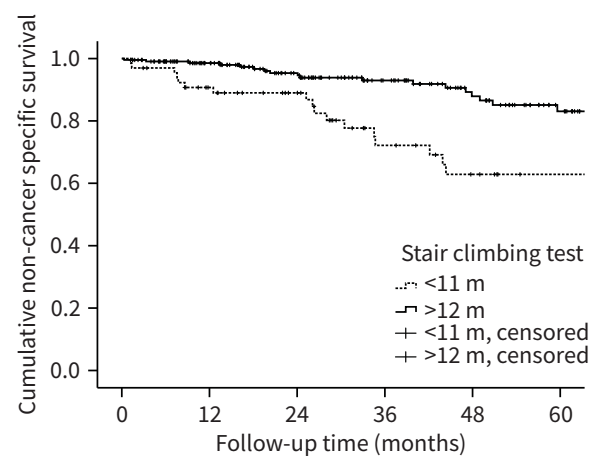

FIGURE 2 a) Overall survival, b) lung-cancer-specific survival and c) non-cancer-specific survival stratified by study group (<11 and $>12$ in stair-climbing test).

In addition to climbed height, desaturation, heart rate change and time are exposures that could be measured during the SCT. Owing to a lack of data we could not use desaturation in the analysis. To simplify the testing, we did not include time or heart rate change as exposures, either. Although the average speed of ascent is a good predictor of $V_{\mathrm{O}_{2}}^{\prime}$ max, the climbed height correlated well with the measured $V_{\mathrm{O}_{2}}^{\prime} \max$ in the relatively few CPET patients in this study [16]. Furthermore, a relatively slow ascending speed of

a)

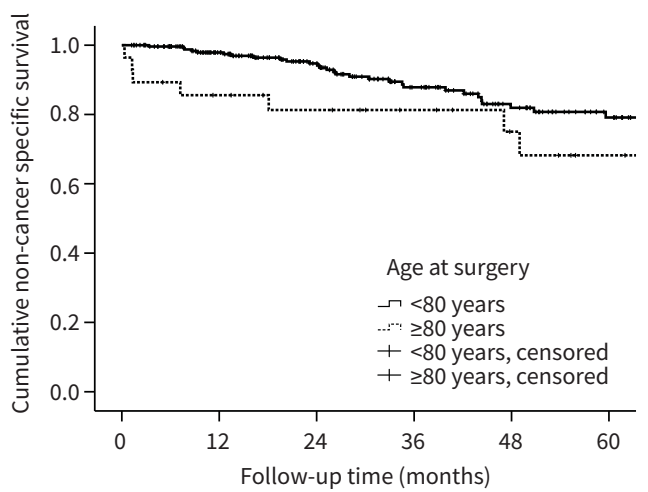

c)

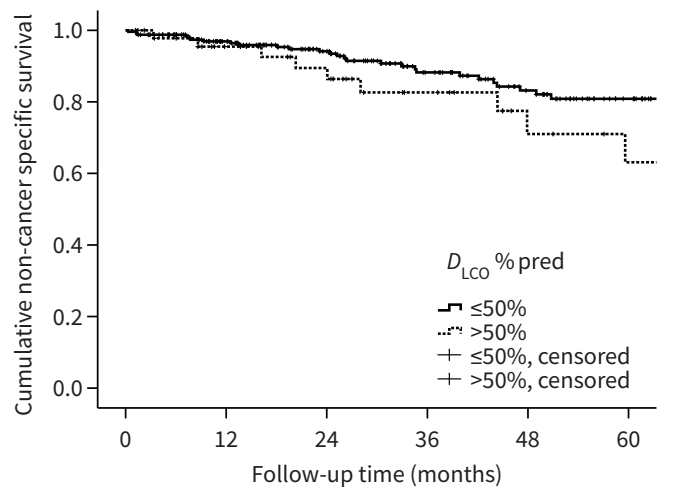

b)

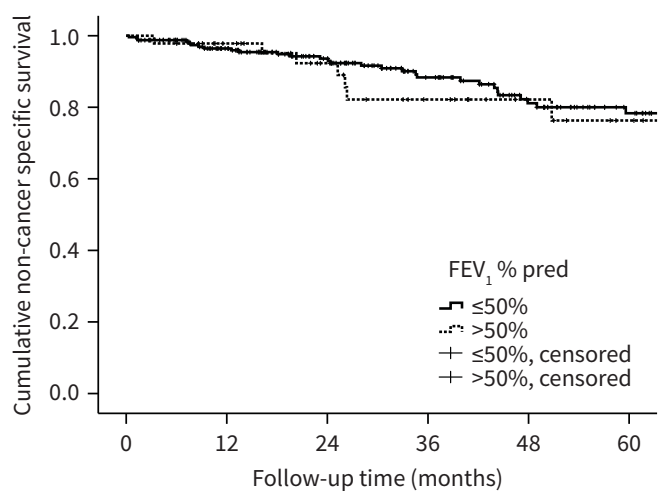

d)

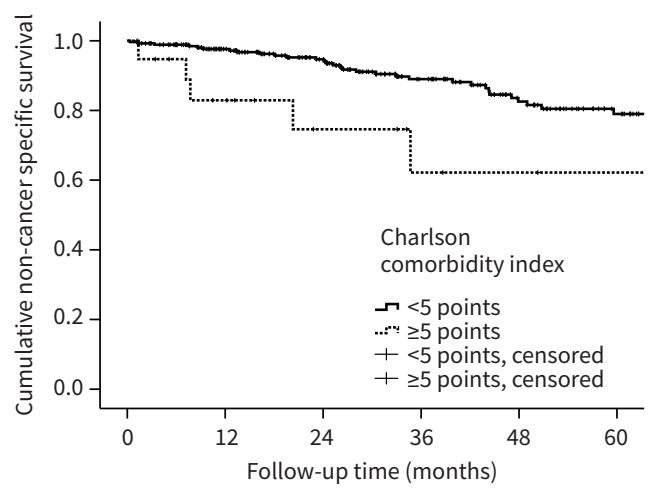

FIGURE 3 Non-cancer-specific survival stratified by other patient-related risk factors including a) age, b) predicted post-operative (ppo) forced expiratory volume in $\left.1 \mathrm{~s}\left(\mathrm{FEV}_{1}\right), \mathrm{c}\right)$ ppo diffusing capacity of the lung for carbon monoxide $\left(D_{\mathrm{LCO}}\right)$ and d) Charlson comorbidity index. 
$11 \mathrm{~m} \cdot \mathrm{min}^{-1}$, of which most people are capable, predicts $V_{\mathrm{O}_{2}}^{\prime} \max$ of $15 \mathrm{~mL} \cdot \mathrm{kg}^{-1} \cdot \mathrm{min}^{-1}$ [16]. Therefore, patients were instructed to climb at their own speed without stopping until exhaustion or at least four floors equalling $14.1 \mathrm{~m}$. In most patients, their maximal height was not reached, and none of the patients were tested up to the guideline threshold for safe surgery of $22 \mathrm{~m}$ [3, 4, 8]. With a guideline-guided approach we have been able to almost double our resection rate in these two geographical areas in Finland, mainly due to a higher number of high-risk patients operated [6]. In our district, the mean age of operated patients is 3 years older than the last published national mean age of 66.6 years [2]. Therefore, this policy of evaluating the physical fitness of every lung cancer surgical candidate and relying on this simplified height-based climbing testing with a maximum test height of $14.1 \mathrm{~m}$ seems practical and enables safe operation of truly high-risk patients as well.

The major strength of this study is the population-based design including two geographical areas in Finland. Unlike many population-based studies, we had full access to all medical records. Therefore, we were able to collect accurately all patient demographics including risk factors, details regarding the treatment and follow-up data. Complete follow-up data were also available from multiple sources. Surgical reports were of importance, since data based only on surgical codes can be misleading and inaccurate in terms of surgical details such as the type of lymphadenectomy. Furthermore, unlike any registry information, complications based on hospital records and a prospective surgical database provide more accurate rates and severity without missing data. The availability of data on routine follow-up and treatment of any possible recurrences in the same hospitals enabled us to collect any cancer recurrences. Medical records of general practitioners treating chronic illnesses and reporting out-of-hospital causes of deaths in these two geographical areas completed the data on cause-specific mortality. Only the cause of death of one patient who died suddenly at home without knowledge of disease recurrence remained unclear. Therefore, we believe that the lung-cancer-specific and non-cancer-specific causes of death have been classified reliably. The limited study population and retrospective design, though much of the data were prospectively collected, were weaknesses of this study.

\section{Conclusions}

In the VATS era, lung cancer surgery can be performed safely with a similar major morbidity rate in the poor performance group $(<11 \mathrm{~m})$ compared to the $>12 \mathrm{~m}$ exercise capacity group. Routine SCT in lung cancer patients predicts the ability to live at home 1 year after surgery and overall survival. In the VATS era, formal CPET seems not to be necessary in patients climbing $>9$ metres. Based on this study, SCT is a potential parameter to be included in every prognostic model of lung cancer eligible for surgery.

Author contributions: 1) conception and design, E. Sihvo; 2) administrative support, all authors; 3) provision of study materials or patients, all authors; 4) collection and assembly of data, all authors; 5) data analysis and interpretation, O. Helminen and E. Sihvo; 6) manuscript writing, all authors; 7) final approval of manuscript, all authors.

Data availability: Data is available upon request from the corresponding author. Data sharing requires additional ethical board review.

Ethical statement: The study was approved by the hospital districts. Because of the retrospective nature of the study, patient informed consent or ethical statement was not required. The authors are accountable for all aspects of the work in ensuring that questions related to the accuracy or integrity of any part of the work are appropriately investigated and resolved.

Conflict of interest: None declared.

Support statement: This study was supported by Finnish State Research Funding, the Instrumentarium Science Foundation, and the Georg C. and Mary Ehrnrooth Foundation. The funders had no role in study design, data collection and analysis, decision to publish, or preparation of the manuscript. Funding information for this article has been deposited with the Crossref Funder Registry.

\section{References}

1 Salati M, Brunelli A, Decaluwe H, et al. Report from the European Society of Thoracic Surgeons Database 2017: patterns of care and perioperative outcomes of surgery for malignant lung neoplasm. Eur $J$ Cardio-thoracic Surg 2017; 52: 1041-1048.

2 Gunn J, Valo J, Sipilä J, et al. Trends and results of lung cancer surgery in Finland between 2004 and 2014. Eur J Cardiothorac Surg 2018; 54: 127-133. 
cancer patients (surgery and chemo-radiotherapy). Eur Respir J 2009; 34: 17-41.

4 Brunelli A, Kim AW, Berger KI, et al. Physiologic evaluation of the patient with lung cancer being considered for resectional surgery: diagnosis and management of lung cancer, 3rd ed: American College of Chest Physicians evidence-based clinical practice guidelines. Chest 2013; 143: Suppl. 5, e166S-e190S.

5 Boujibar F, Gillibert A, Gravier FE, et al. Performance at stair-climbing test is associated with postoperative complications after lung resection: a systematic review and meta-analysis. Thorax 2020; 75: 791-797.

6 Helminen $\mathrm{O}$, Valo $\mathrm{J}$, Andersen $\mathrm{H}$, et al. Real-world guideline-based treatment of lung cancer improves shortand long-term outcomes and resection rate: a population-based study. Lung Cancer 2020; 140: 1-7.

7 Dindo D, Demartines N, Clavien PA. Classification of surgical complications: a new proposal with evaluation in a cohort of 6336 patients and results of a survey. Ann Surg 2004; 240: 205-213.

8 Detterbeck FC, Lewis SZ, Diekemper R, et al. Executive summary. Chest 2013; 143: 7S-37S.

9 Myers J, Prakash M, Froelicher V, et al. Exercise capacity and mortality among men referred for exercise testing. N Engl J Med 2002; 346: 793-801.

10 Brunelli A, Pompili C, Berardi R, et al. Performance at preoperative stair-climbing test is associated with prognosis after pulmonary resection in stage I non-small cell lung cancer. Ann Thorac Surg 2012; 93: 1796-1800.

11 Win T, Sharples L, Groves AM, et al. Predicting survival in potentially curable lung cancer patients. Lung 2008; 186: 97-102.

12 Solomon A, Borodulin K, Ngandu T, et al. Self-rated physical fitness and estimated maximal oxygen uptake in relation to all-cause and cause-specific mortality. Scand J Med Sci Sport 2018; 28: 532-540.

13 Onaitis MW, Furnary AP, Kosinski AS, et al. Prediction of long-term survival after lung cancer surgery for elderly patients in The Society of Thoracic Surgeons General Thoracic Surgery Database. Ann Thorac Surg 2018; 105: 309-316.

14 Brunelli A, Chaudhuri N, Kefaloyannis M, et al. Eurolung risk score is associated with long-term survival after curative resection for lung cancer. J Thorac Cardiovasc Surg 2021; 161: 776-786.

15 Crandall K, Maguire R, Campbell A, et al. Exercise intervention for patients surgically treated for Non-Small Cell Lung Cancer (NSCLC): a systematic review. Surg Oncol 2014; 23: 17-30.

16 Koegelenberg CFN, Diacon AH, Irani S, et al. Stair climbing in the functional assessment of lung resection candidates. Respiration 2008; 75: 374-379. 